\title{
Analysis of Poul Gernes' painted folding doors at Herlev Hospital
}

\author{
Anna Katrine Hansen ${ }^{1}$, Marie Bitsch Christiansen², Jana Sanyova ${ }^{3}$ and Kim Pilkjær Simonsen ${ }^{1 *}$ (])
}

\begin{abstract}
An analytical study of the painted folding doors at Herlev Hospital in Denmark has been performed in connection with the creation of new doors. The hospital which construction was completed in 1976 is one of the first polychrome hospitals in the world. The building has achieved international awareness not only as a piece of architecture but also as an artwork being the largest artistic decoration of a public space in Denmark. Besides the decoration of the walls and interior which colour scheme was designed by the Danish artist Poul Gernes, the hospital foyer includes 65 individual paintings and two painted folding doors, which were executed by Poul Gernes. The folding doors are the original doors from 1976 and have never been restored. The paint used for the decoration of the folding doors were analysed by micro-Raman spectroscopy, scanning electron microscopy-energy dispersive X-ray spectroscopy, microFourier transform infrared spectroscopy, and pyrolysis-gas chromatography-mass spectrometry. The results showed, that the variant colours were created by the use of a limited number of pigments and consist of a mixture of inorganic pigments and synthetic organic pigments. The detected pigments were chrome yellow, chrome orange/chrome red, PY3, PR3, PR122, PB15, and PV23. Titanium white (rutile) was found in all paint and preparatory layers, and it was used as both a whitening agent in mixtures with other pigment and a filler material in the paint. The study also shows how the decorations were created and it hence relates to other studies of wall paintings from that period giving useful information for future restoration issues about the possible pigments and binder used.
\end{abstract}

Keywords: Poul Gernes, Herlev Hospital, Paintings, Alkyd paint, Pigments, SOPs

\section{Background}

The Danish artist Poul Gernes (1925-1996), one of the founders of the so-called Ex-school (the Experimental Art School, 1961-1969), is known for his large and colourful decorations of public spaces in Denmark. His works include the decoration of several schools, a dormitory, a town hall, and not least the provocative colouring of the facade of the Palads Cinema, a landmark building in downtown Copenhagen, and the interior and walls of Herlev Hospital at the outskirts of Copenhagen [1]. The decorations by Poul Gernes are characterised by strong and vivid colours and often with simple clear shapes and geometric patterns. Gernes believed that ornamentation had a social effect and a positive emotional influence, and in 1988 he represented Denmark at the Venice Biennial

\footnotetext{
${ }^{*}$ Correspondence: kps@kadk.dk

${ }^{1}$ School of Conservation, Esplanaden 34, 1263 Copenhagen K, Denmark Full list of author information is available at the end of the article
}

where he spread his view on the stimulating effect of colours [1]. Gernes also believed that colours could have a stimulating effect on hospital patients in favour of distraction from their pain and suffering [1].

With its colourful decoration of the walls and interior, Herlev Hospital is considered one of the masterpieces of Poul Gernes and when the construction was completed in 1976 it was one of the first polychrome hospitals in the world.

The building, designed by the Danish modernist architects Gehrdt Hinrich Bornebusch, Max Brüel and Jørgen Selchau, has achieved international awareness not only as a piece of architecture presenting a vision of integration of colour, form and function but also as an artwork being the largest artistic decoration of public space in Denmark [1]. Besides the colour scheme for decoration of the walls and interior designed by Gernes, the hospital foyer includes 65 individual paintings and two painted folding doors executed by Poul Gernes [1]. (Originally, 
there were four folding doors but the two doors at the balcony covering a bank and a hairdressing salon were removed around 2003 and replaced by glass walls, when the shops were closed down). The two remaining folding doors are the original doors from 1976 and have never been restored.

The function of the doors is to cover the two shops, a kiosk and a flower shop, placed in the foyer.

The folding doors are of the type mobile partitioning i.e. a system of sliding door leafs where the individual leafs are suspended in a track mounted on the ceiling. The doors consist of six door leafs measuring $130 \times 250 \mathrm{~cm}$ each. On both sides of each door leaf a painted panel made of MDF wood (Medium Density Fibreboard) is attached so that when the doors are closed each of the four different connected decorations of $c .20 \mathrm{~m}^{2}$ are visible (Fig. 1). The decorations named front can be seen in the foyer whereas the decorations named back can only be observed from the inside of the shops. During the day, the panels are stacked at the side of the shop entrance.

Since the doors have been handled daily, when opening and closing the shops, the decorations were in a critical condition due to several damages caused by collisions with store fixtures. In addition, the mechanical parts of the folding doors were worn out in such a degree that any conservation treatment would have been unaffordable. It was therefore decided that new doors had to be recreated and that the original doors should be stored at Museum of Art in Public Spaces and the paint used by Gernes should be investigated. Samples representing each colour were therefore taken for pigment analysis.

It is known that Poul Gernes until the mid-1970s had a close collaboration with the Danish paint factory Beck \& Jørgensen, and afterwards with the paint factory Flügger and their colour engineer Willum Thomsen (personal information from Poul Gernes' daughter Ulrikka Gernes). It is therefore possible that one or both of these companies produced the house paints used for the decorations at Herlev Hospital. However, no records of the actual paints and their composition have been available, and to our knowledge this is the first analysis of the paints used by Poul Gernes.

\section{Experimental}

\section{Cross sections}

Paint samples were taken from the folding doors and prepared as cross sections by embedding them in Technovit 2000 LC light curing resin placed in EasySections. The resin was cured for 10 min with blue light under a flow of nitrogen gas in a light-curing oven (Egger EL 1 plus $\mathrm{N}_{2}$ ). The cross sections were polished wet with silicon carbide and then dry with Micro-Mesh ${ }^{\circledR}$ (granularity 2400-12,000).
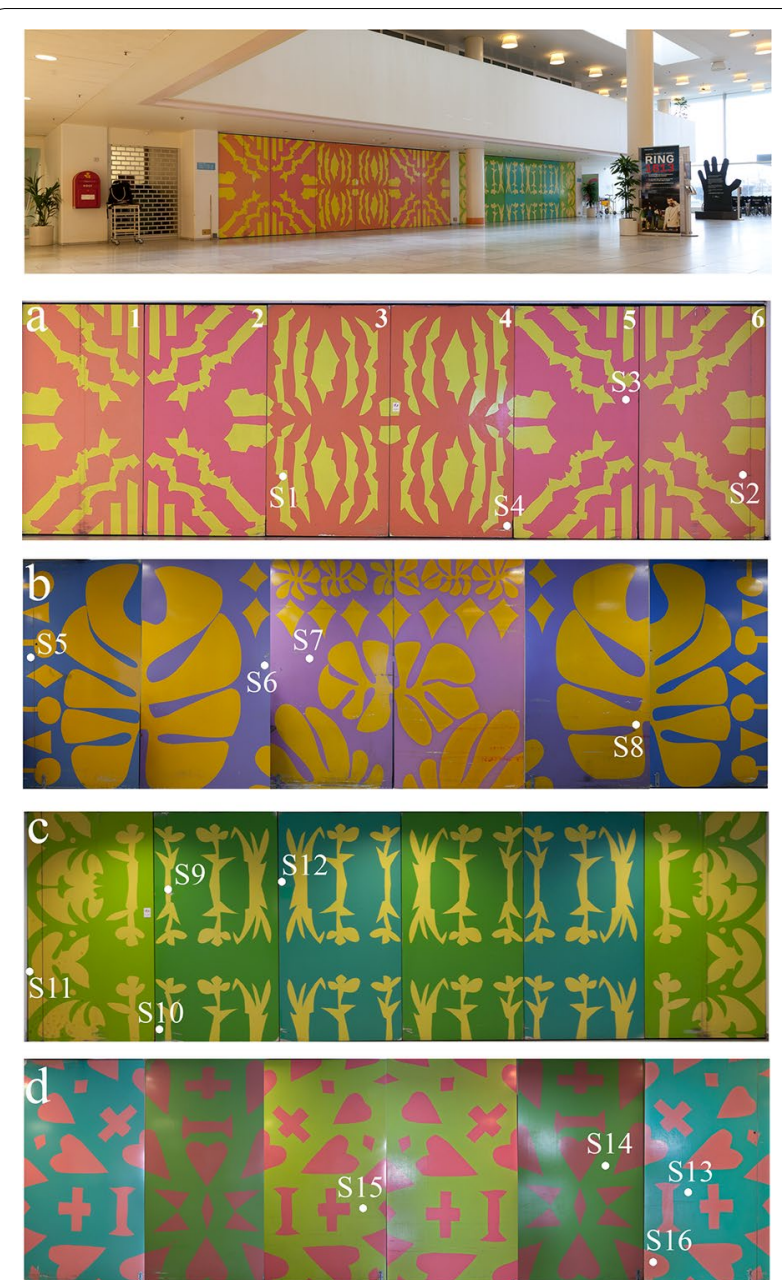

Fig. 1 Top: Photograph of the closed folding doors in foyer at Herlev Hospital. Below: Photographs of a Kiosk front, b Kiosk back, c Flower front, and $\mathbf{d}$ Flower back, with marking of the samples taken and panel numbers

\section{Optical microscopy (OM)}

Cross sections were studied with an optical microscope Axio Imager M1 (Carl Zeiss) under polarised white light and ultraviolet radiation with magnifications between 100 and $500 \times$.

\section{Raman}

Micro-Raman spectrometer analyses were performed on cross sections at IRPA/KIK with a Renishaw inVia dispersive micro-Raman spectrometer equipped with a $785 \mathrm{~nm}$ laser. The laser power was kept between 0.1 and $1 \mathrm{~mW}$ by neutral density filters to avoid thermal degradation. A detailed description can be found in Ref. [2].

\section{SEM-EDS}

Scanning electron microscopy-energy dispersive X-ray spectroscopy (SEM-EDS) analyses were carried out on 
cross sections using a Hitachi S-3400N scanning electron microscope with an energy dispersive X-ray spectrometer (SEM-EDS) operating at an acceleration voltage of $20 \mathrm{kV}$ and low vacuum mode at $25 \mathrm{~Pa}$. The EDS system, QUANTAX 200, was equipped with two $30 \mathrm{~mm}^{2}$ SDD X-ray detectors (XFlash ${ }^{\circledR} 6 \mid 30$ Silicon Drift Detector) from Bruker instruments.

\section{$\mu-\mathrm{FTIR}$}

Micro-Fourier transform infrared spectroscopy ( $\mu$-FTIR) spectra of the preparation layers were performed in ATR mode on cross sections in the range of $4000-600 \mathrm{~cm}^{-1}$ with a resolution of $4 \mathrm{~cm}^{-1}$ acquired over 64 scans using a Hyperion 3000 spectrometer equipped with a Mercury Cadmium Telluride (MCT) detector cooled with liquid nitrogen. ( $\mu$-FTIR analyses were performed at IRPA/ KIK).

\section{Py-GC-MS}

Pyrolysis-gas chromatography-mass spectrometry (PyGC-MS) analyses were performed at IRPA/KIK. Prior to the Py-GC-MS analysis, the solid sample was placed in a glass vial and put into suspension with $15 \mu \mathrm{L}$ of a $2.5 \%$ solution of tetramethylammonium hydroxide (TMAH) in methanol, and $4 \mu \mathrm{L}$ of the suspension was placed in a stainless steel Eco-cup containing an Auto-Rx disc. $1 \mu \mathrm{L}$ of $\mathrm{C} 17$ internal standard was added into the Ecocup and the Eco-cup was placed in the Frontier lab AS1020ET auto sampler. The pyrolysis interface was purged with helium and the sample was pyrolysed at $550{ }^{\circ} \mathrm{C}$ for $12 \mathrm{~s}$. The pyrolysis unit was a multi-shot pyrolyser EGA/ PY-3030D attached to a Trace GC 2000 chromatograph coupled to a Finnigan PolarisQ ion trap MS detector. Pyrolysis interface to the column was kept at $250^{\circ} \mathrm{C}$. Separations were accomplished on a SLB-5 ms capillary column. Helium was used as carrier gas at a constant flow of $0.9 \mathrm{~mL} \mathrm{~min}{ }^{-1}$. The temperature program adopted was an initial temperature of $35^{\circ} \mathrm{C}$ maintained for 1 min during split injection (split ratio 20). Then a $10^{\circ} \mathrm{C} \mathrm{min}^{-1}$ gradient was applied until $320^{\circ} \mathrm{C}$ and this temperature was maintained for $5 \mathrm{~min}$. The MS transfer line was maintained at $290{ }^{\circ} \mathrm{C}$ during the whole procedure. Ionization was carried out in the ion volume of the ion trap mass spectrometer under the standard EI positive mode at $70 \mathrm{eV}$. The mass spectrometer was scanned from $\mathrm{m} / z 35$ to 500 with a cycle time of $0.5 \mathrm{~s}$. The data was processed with Xcalibur 1.4 software.

\section{Results and discussion}

\section{Preparatory layers}

Before the background colour and the design pattern were painted, two preparatory layers were applied on the MDF panels. The two distinctive layers can be seen under UV-light in OM due to the different fluorescence of the layers and in backscattered electron images (BSE) (Fig. 2c, d). Raman and SEM-EDS analyses showed that the first layer mainly consisted of large crystals of barite $\left(\mathrm{BaSO}_{4}\right)$, fibrous crystals of talc $\left(\mathrm{Mg}_{3} \mathrm{Si}_{4} \mathrm{O}_{10}(\mathrm{OH})_{2}\right)$, and small particles of titanium white $\left(\mathrm{TiO}_{2}\right)$ of the rutile type. In the Raman spectrum seen in Fig. 3a rutile is identified by its two characteristic broads bands at 610 and $448 \mathrm{~cm}^{-1}$ [2-4], barite by the sharp symmetrical S-O stretching at $988 \mathrm{~cm}^{-1}[4,5]$, and talc by the $\mathrm{Si}-\mathrm{O}-\mathrm{Si}$ stretching and bending modes at 676 and $363 \mathrm{~cm}^{-1}$, and the lattice vibration at $192 \mathrm{~cm}^{-1}[6,7]$. SEM-EDS analysis indicated the presence of a minor amount of magnesium oxide $(\mathrm{MgO})$, and potassium-iron containing aluminium silicate which could be of a mica type $\left(\mathrm{K}_{2}\left(\mathrm{Al}_{6} \mathrm{Si}_{6} \mathrm{O}_{20}\right)\right.$ $\left.(\mathrm{OH})_{4}\right)$ present in the first preparatory layer.

The second preparatory layer consisted mainly of calcite $\left(\mathrm{CaCO}_{3}\right)$ mixed with rutile together and a smaller amount of fibrous talc and potassium-iron containing aluminium silicate. Calcite particles appeared subrounded and semi-transparent and were identified by IR from the characteristic broad asymmetric $\mathrm{C}-\mathrm{O}$ stretching around $1400 \mathrm{~cm}^{-1}$, the sharp out of plane bending vibration at $873 \mathrm{~cm}^{-1}$, and the asymmetric $\mathrm{C}-\mathrm{O}$ bending at $712 \mathrm{~cm}^{-1}$ [8] as shown in Fig. 3b. Talc was identified by the $\mathrm{O}-\mathrm{H}$ stretch at $3677 \mathrm{~cm}^{-1}$, the $\mathrm{Si}-\mathrm{O}-\mathrm{Si}$ stretch at $1010 \mathrm{~cm}^{-1}$, and the bending vibration at $667 \mathrm{~cm}^{-1}$ [7]. The binding medium was identified as an alkyd by the $\mathrm{C}=\mathrm{O}$ stretching vibration at $1726 \mathrm{~cm}^{-1}$, the $\mathrm{C}-\mathrm{O}$ stretches at 1263 , and $1118 \mathrm{~cm}^{-1}$, the aromatic $\mathrm{C}=\mathrm{C}$ in-plane deformation at $1068 \mathrm{~cm}^{-1}$, and the weak aromatic $\mathrm{C}=\mathrm{C}$ stretching vibrations at 1599 and $1579 \mathrm{~cm}^{-1}$ which proposed an ortho-phthalate alkyd [9-13]. The relative intense $\mathrm{C}-\mathrm{H}$ stretching absorption at 2917 and $2850 \mathrm{~cm}^{-1}$ suggested an oil modified alkyd formulation $[2,14]$.

\section{Binding medium}

Pyrolysis-gas chromatography-mass spectrometry analyses were carried out on a sample from Kiosk back (S8). The sample was separated into the yellow design pattern layer, the blue violet background layer, and the calcite containing preparatory layer. All analyses resulted in chromatograms similar to the one shown in Fig. 4, confirming an oil modified alkyd binding medium based on ortho-phthalic acid. Minor amounts of $i s o$-phthalic resin and rosin compounds were also found. $\left(\mathrm{m} / \mathrm{z}\right.$ and $R_{T}$ values are listed in Additional file 1: Table S1).

The monocarboxylic acids are related to the oil modification and suberic and azealic acid are common oxidation products of a siccative oil $[11,15]$. Based on the relative peak heights of ortho-phthalic acid and of the fatty acids the oil length of the alkyd resin is likely to be a 

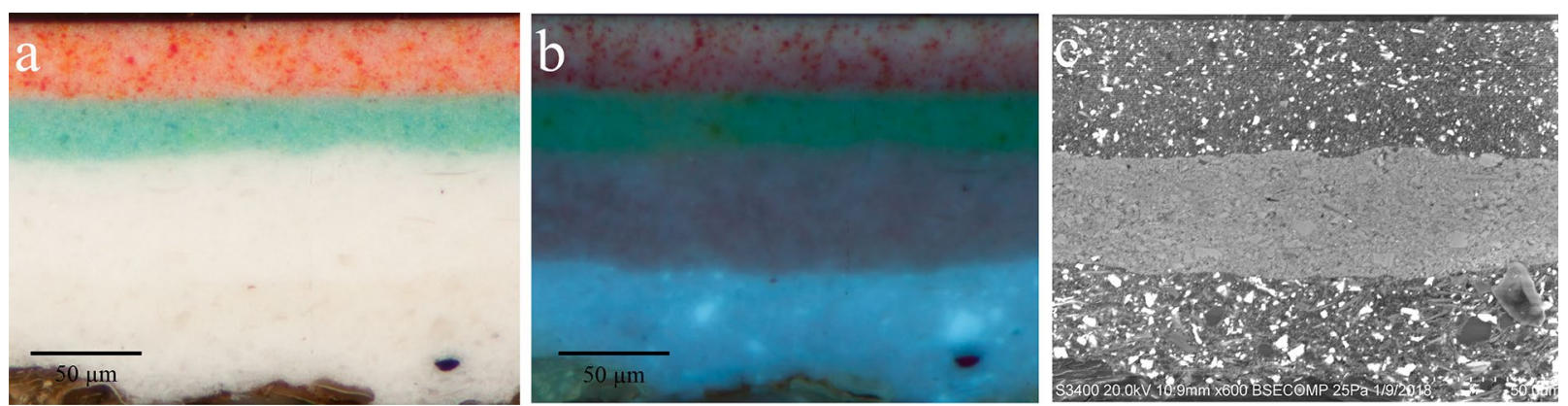

Fig. 2 Details of cross section S16 from Flower back showing the pink design pattern on top of the bluish green background colour depicted in a polarised light, $\mathbf{b}$ UV light, and $\mathbf{c}$ back scattered electron (BSE) image. The two preparatory layers can be observed by their different fluorescence in UV light and by BSE
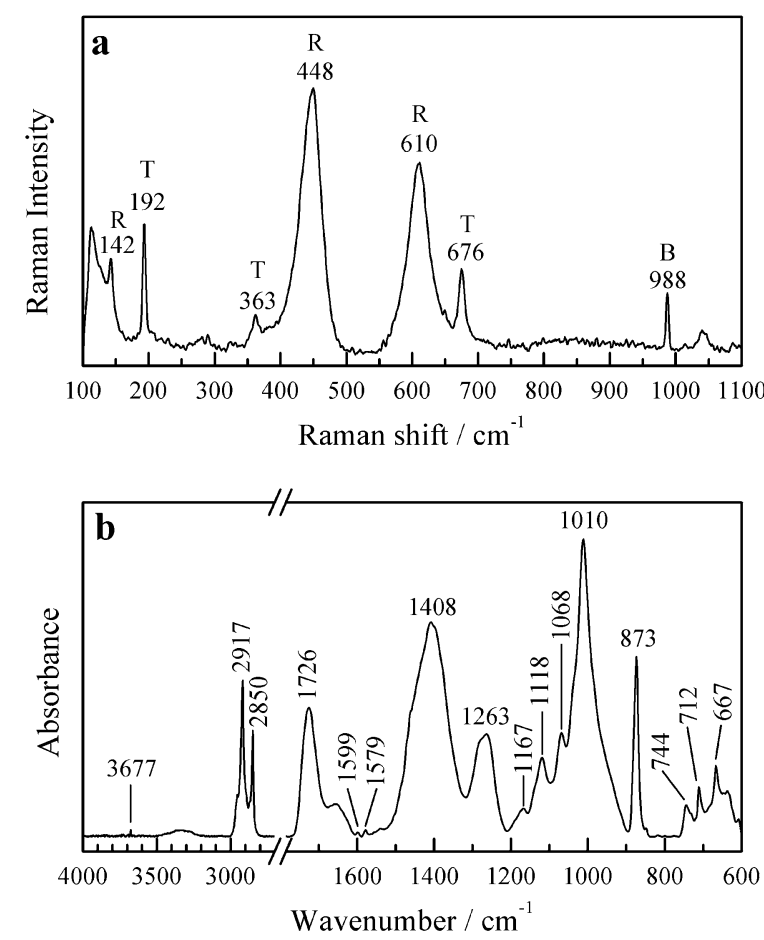

Fig. 3 a Raman spectrum showing the presence of barite (B), rutile $(\mathrm{R})$, and talc ( $\mathrm{T}$ ) in the first preparatory layer, and $\mathbf{b} \mathrm{IR}$ spectrum showing calcite, talc, and alkyd binding medium in the second preparatory layer

medium type [16]. The rosin compounds identified were dehydroabietic acid (DHA), 7-oxo DHA, and 7-methoxytetradehydroabietic acid which are oxidation products of abietic acid and markers for resin of the Pine tree family (Pinaceae) [17-20]. The presence rosin may indicate that oil modification was performed with tall oil fatty acids (TOFA), a by-product from the paper industry which finds major use in alkyds $[2,15]$. However, a direct addition of rosin to the oil modified alkyd or pigment modification can not be excluded.

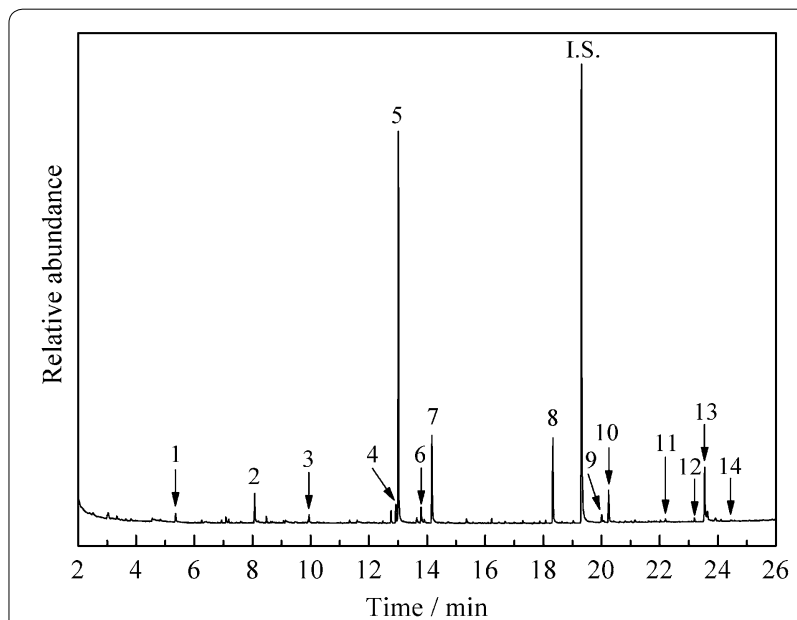

Fig. 4 Chromatogram of a sample (S8) from the blue violet paint layer from Kiosk back. The peak marked I.S. is the internal standard (methyl ester of margaric acid, C17:0). The strong peak no. 5 corresponds to the dimethyl ester of ortho-phthalic acid and the minor peak no. 6 to the dimethyl ester of iso-phthalic acid. Methyl benzoate, peak no. 2, is most likely derived from fragmentation of the phthalic acid component. The methyl ester compounds of the monocarboxylic acids caproic (C6:0), capric (C10:0), palmitic (C16:0), oleic (C18:1), stearic (C18:0), and of the dicarboxylic acids suberic (2C8) and azelaic (2C9) are seen at peaks nos. 1, 3, 8, 9, 10, 4, and 7, respectively. The identified rosin compounds dehydroabietic acid (DHA), 7-oxo DHA, and 7-methoxy-tetradehydroabietic acid are seen at peak nos. 11, 12, and 14, respectively. Peak no. 13 is unknown. $(\mathrm{m} / \mathrm{z}$ and $R_{T}$ values are listed in Additional file 1:Table S1)

The compound represented in peak no. 13 was not identified. The mass spectrum showed the characteristic homologous series of ions for a long chain carbon back bone $(\Delta m / z=14)$, but whether this compound originates from the oil modification or a paint additive is unknown.

The polyfunctional alcohol was not detected by the Py-GC-MS method, perhaps due to the instrumentation. However, by extraction of a paint sample with 50:50 chloroform/methanol mixture followed by evaporation a 
small amount of the binder was isolated. ATR-FTIR analysis of the binder showed a spectrum typical of orthoalkyd and with a broad $\mathrm{C}-\mathrm{H}$ bending frequency from 1460 to $1440 \mathrm{~cm}^{-1}$ indicating that both pentaerythritol and glycerol were used as polyfunctional alcohols $[2,10]$.

\section{Background colour and design pattern}

The painting technique was indicated from the visual inspection of the doors, and is in accordance with the description of the technique given by Poul Gernes' daughter Ulrikka Gernes [1]. Due to the structure of the paint film that has a texture similar to an orange peel, the use of a paint roller for both the background colour and design pattern was possible. In addition to this, the application of a simple stencilling technique was also observed since "woolly edges" were seen where the paint had been flowing under the stencil. In Fig. 5 photographs of the paint surface with this characteristic texture, and damages in the paint layer are shown.

As seen in Fig. 1 each side of a door consists of four colours: The colour of the design pattern which is the same for each side of a door (painted stencilling technique), and the background colour which consists of three different colour nuances. For three of the folding doors, Kioks front, Kiosk back, and Flower back, the six door panels are symmetrical in their background colouration with 1 and 6, 2 and 5, and two middle panels 3 and 4 having the same colour. For the Flower front the panels 1 and 6 , 2 and 4, and 3 and 5 have the same background colour. Samples representing the 16 different colours were taken as indicated in Fig. 1, and an overview of the pigments identified is given in Table 1.

Among the inorganic materials, titanium white was present in all samples and most likely used as both a filler material and a whitening agent. A minor amount of barite was found in approximately half of the samples; however, it might have been used as a filler in all the paint.
For simplicity, both rutile and barite are omitted from Table 1.

The only coloured inorganic pigment found in the examined cross sections was lead chromate, which was found in all the design patterns and in several of the background colours. Lead chromate was present as either chrome yellow $\left(\mathrm{PbCrO}_{4}\right)$ or chrome orange/chrome red $\left(\mathrm{PbCrO}_{4} \cdot \mathrm{PbO}\right)$. Mixtures of the chromate pigments were also used as observed by OM and Raman spectroscopy (sample S8, Fig. 6a). From the Raman spectrum the mixture was identified by the strong symmetric $\mathrm{Cr}-\mathrm{O}$ vibration at $839 \mathrm{~cm}^{-1}$ of chrome yellow overlapped with the characteristic $\mathrm{Cr}-\mathrm{O}$ bands at 825 and $847 \mathrm{~cm}^{-1}$ from chrome orange, and from the two strongest bending modes at 359 and $343 \mathrm{~cm}^{-1}$ belonging to chrome yellow and chrome orange, respectively. The bending mode at $402 \mathrm{~cm}^{-1}$ is also ascribed to chrome yellow, while the bands at 381 and $325 \mathrm{~cm}^{-1}$ are assigned as overlaps from both pigments $[4,21-23]$.

Beside the use of lead chromates as pure colouring pigments, these were also used together with SOPs like PY3 for shades of yellow or PR3 for pink. The absence of green pigments should is noticeable. The green colours were made by mixing blue and yellow e.g. chrome yellow and PB15, or PY3 and PB15. This is possibly due to financial aspects in fabrication of house paint as lowcost green shades combining PB15 with yellow pigments are cheaper than e.g. the green copper phthalocyanine complex PG7 or chromium oxide greens $\left(\mathrm{Cr}_{2} \mathrm{O}_{3}\right.$ or $\left.\mathrm{Cr}_{2} \mathrm{O}_{3} \cdot 2 \mathrm{H}_{2} \mathrm{O}\right)[24,25]$.

The most abundant SOP used for the decoration of the doors was the copper phthalocyanine blue, PB15. PB15 was also mixed and toned with other SOPs like PV23 and PR122 for shades of blue and violet colours. The pigment PB15 was identified by MRS by its strong scattering and the characteristic and distinct bands at 1529, 1451, 1342,

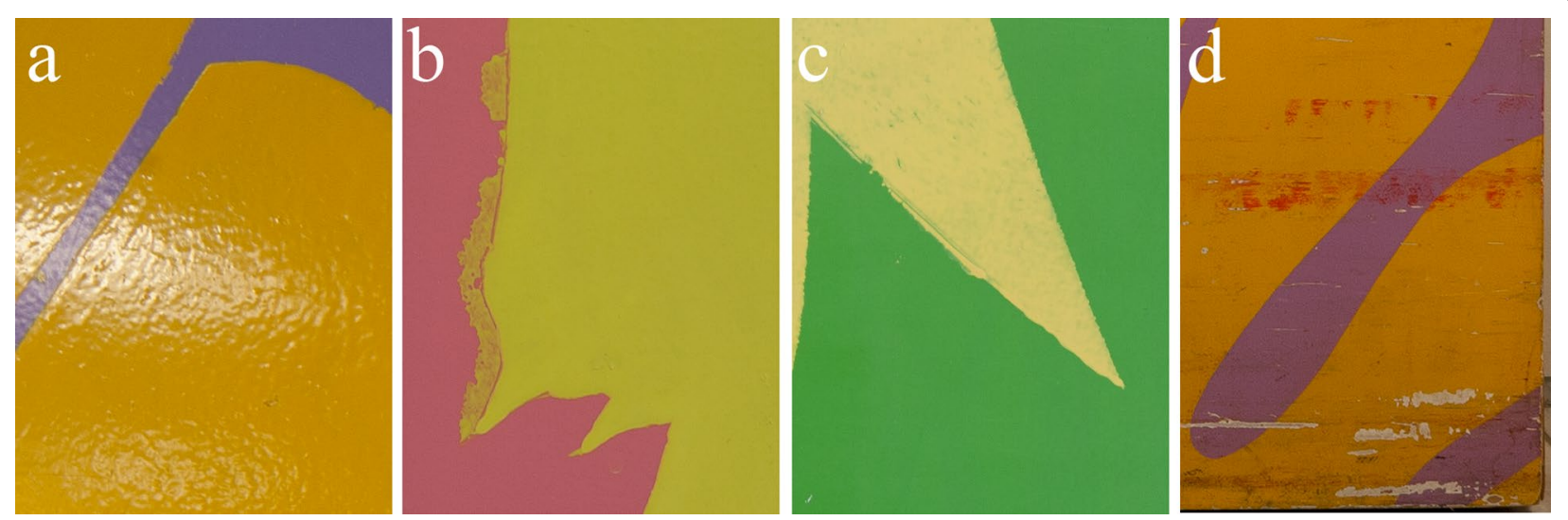

Fig. 5 Photographs of the paint film surface showing a the orange peel texture, $\mathbf{b}$ and $\mathbf{c}$ the "woolly edges", and $\mathbf{d}$ damages to the door decoration 
Table 1 Pigments identified by Raman and SEM-EDS in the background colours and design patterns

\begin{tabular}{|c|c|c|c|c|}
\hline \multicolumn{2}{|l|}{ Paint layer } & \multicolumn{2}{|c|}{ Background colour } & \multirow{2}{*}{$\begin{array}{l}\text { Design pattern } \\
\text { All, 1-6 }\end{array}$} \\
\hline Kiosk front, panel nos. & 1,6 & 2,5 & 3,4 & \\
\hline Colour & Light orange & Pink & Orange & Yellow \\
\hline \multirow[t]{4}{*}{ Pigments } & Chrome orange & PR3 & Chrome orange & Chrome yellow \\
\hline & Chrome yellow & & & Chrome orange \\
\hline & & & & PY3 \\
\hline & & & & PB15 \\
\hline Kiosk back, panel nos. & 1,6 & 2,5 & 3,4 & All, 1-6 \\
\hline Colour & Blue & Blue violet & Violet & Yellow \\
\hline \multirow[t]{2}{*}{ Pigments } & PB15 & PB15 & PB15 & Chrome yellow \\
\hline & PV23 & PR122 & PR122 & Chrome orange \\
\hline Flower front, panel nos. & 1,6 & 2,4 & 3,5 & All, 1-6 \\
\hline Colour & Light green & Green & Blue green & Yellow \\
\hline \multirow[t]{2}{*}{ Pigments } & PB15 & PB15 & PB15 & Chrome yellow \\
\hline & Chrome yellow & Chrome yellow & Chrome yellow & \\
\hline Flower back, panel nos. & 1,6 & 2,5 & 3,4 & All, 1-6 \\
\hline Colour & Bluish green & Green & Light green & Pink \\
\hline \multirow[t]{2}{*}{ Pigments } & PB15 & PB15 & PB15 & Chrome orange \\
\hline & PY3 & Chrome yellow & Chrome yellow & PR3 \\
\hline
\end{tabular}

Rutile is omitted as present in all colours

$1143,954,748,681$, and $484 \mathrm{~cm}^{-1}$ caused by vibrations of the porphyrin ring $[13,26,27]$.

An example of the preparation of green by mixing blue and yellow is seen in sample S10 from Flower front. In the Raman spectrum in Fig. 6b bands assigned to PB15 appear together with two bands assigned to chrome yellow (841 and $360 \mathrm{~cm}^{-1}$ ) marked $\mathrm{Cr}$.

A shading of the blue colour of PB15 is seen in sample S5 taken from the blue door of Kiosk back in which Raman analysis revealed the presence of the violet pigment PV23. PV23 is one of the most important dioxazine pigments. It is especially used to shade the colour of blue phthalocyanine pigments [24], and also for violet house paint [28]. The Raman spectrum seen in Fig. 6c shows the combined use of PV23 characterised by its bands at 1431, 1393, 1257, 1208, 528 and $316 \mathrm{~cm}^{-1}$ [26-28] and PB15 (marked PB).

The violet colours present in samples S6 and S7 from Kiosk back were made by mixing PB15 with the red quinacridone pigment PR122. This pigment is known for its use as a tinting and shading pigment [24] but is also found in house paint used for mural paintings [28]. PR 122 is characterised by the Raman bands at 1650, 1594, 1567, 1313, 720542 and $308 \mathrm{~cm}^{-1}$ [26-28] as seen in Fig. 6d where bands assigned to PB15 (marked PB) are also present.

The bluish green colour of Flower back (S13) was a mixture of PB15 and yellow acetoacetic arylide azo pigment PY3 also known as Hansa Yellow 10G. PY3, a greenish yellow pigment, is often combined with blue pigments to produce shades of green as in this case [24]. PY3 (commercialised around 1910), has strong and medium Raman bands at 1613, 1494, 1386, 1337, 1309, 1139 and $748 \mathrm{~cm}^{-1}$ together with several minor characteristic bands $[26,27,29]$. The spectrum of PY3 can be seen in Fig. 6e together with PB15 (marked PB). The band at $748 \mathrm{~cm}^{-1}$ marked $\mathrm{PB}+\mathrm{PY} 3$ is an overlap of both pigments making this band intense.

The pink colour of the design pattern (Flower back, S16) was identified as a mixture of the $\beta$-naphthol azo pigment PR3 also known as toluidine red and chromium orange. PR3 was launched on the market in 1905 and together with PY3, belongs to the groups of the earliest azo-pigments. It is one the few $\beta$-naphthol pigments still playing a commercial role [24]. PR3 is well known in modern paintings containing SOPs both alone and in mixtures with lead chromates and/or titanium white, as well as in house paint [30-34]. PR3 is characterised by its multiple sharp and distinct Raman bands such as 1620, 1445, 1333, $1320,1185,1126,383$, and $342 \mathrm{~cm}^{-1}[26,27,29]$. The spectrum of PR3 is shown in Fig. $6 f$ together with chromium orange and rutile marked $\mathrm{Cr}$ and $\mathrm{R}$, respectively. The band at $342 \mathrm{~cm}^{-1}$ marked $\mathrm{Cr}+\mathrm{PR} 3$ is an overlap of the sharp PR3 band and the strongest bending mode of chromium orange making this band very intense.

\section{Conclusions}

This paper has investigated the composition of modern paint material and the stratigraphic build-up of Poul Gernes' folding doors at Herlev Hospital completed in 1976. 

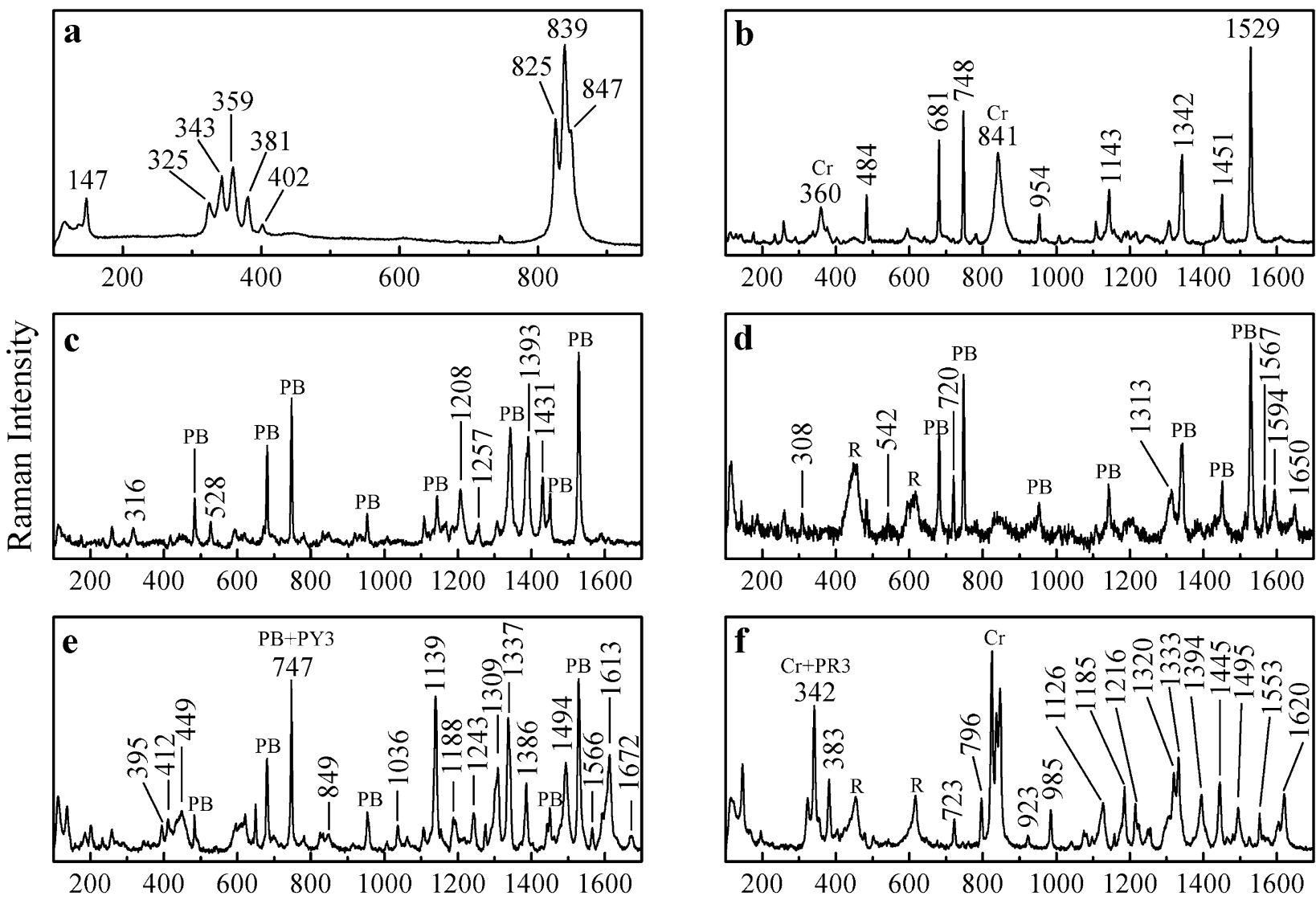

Raman shift $/ \mathrm{cm}^{-1}$

Fig. 6 Raman spectra of pigments identified in the folding doors. The spectra depicted are a mixture of chrome yellow and chrome orange, $\mathbf{b}$ PB15 and chrome yellow, c PB15 and PV23, d PB15, PR122, and rutile, e PB15 and PY3, and f chrome orange, PR3, and rutile

The study relates to other studies of wall paintings from that period giving useful information for future restoration issues about the possible pigments and binders used. The analyses suggested that the decorations were made with alkyd house paints based mainly on ortho-phthalic acid, which is one of the most common dibasic acid used in alkyd house paints, though a smaller amount of iso-phthalic acid was also identified. Pentaerythritol and glycerol were both used as the polyfunctional alcohol.

The 16 different colours were created by the use of a limited number of pigments, i.e. chrome yellow, chrome orange/chrome red, and the SOPs PY3, PR3, PR122, PB15, and PV23. Titanium white was present in all paint and preparatory layers in variable amounts as a whitener in the colour shades. The major SOP used was the blue copper phthalocyanine complex PB15 which was mixed with other SOPs to create shades of blue, bluish green, violet blue, and violet, or with chrome yellow for green colours.

Among the colours, the most notable might be the lack of green pigments. A mixture of blue and yellow pigments created all the green colours. This suggests that the price issue was an important aspect in fabrication of house paint as low-cost green shades combining PB15 with yellow pigments are cheaper than e.g. the green copper phthalocyanine complex PG7 or chromium oxide greens $\left(\mathrm{Cr}_{2} \mathrm{O}_{3}\right.$ or $\left.\mathrm{Cr}_{2} \mathrm{O}_{3} \cdot 2 \mathrm{H}_{2} \mathrm{O}\right)$.

The abundant use of lead chromate pigments in the decorations on the doors is probably due to the fact that lead chromates were a part of typical alkyd paint compositions from the 1920s through their wide distribution in the 1950s and until lead chromate was abolished from house paint due to health risks. However, as lead chromates on the doors are tightly bound in the alkyd matrix their potential hazards are minimal. Breathing of paint dust on the other hand must clearly be avoided and care should in general be taken in connection with restoration of surfaces containing lead chromate.

\section{Additional file}

Additional file 1: Table S1. Main peaks, retention time and molecular weight of THM-GC-MS of the blue violet paint layer (S8) from Kiosk back. 


\section{Authors' contributions}

All authors contributed to data interpretation and to finalizing the manuscript. All authors read and approved the final manuscript.

\section{Author details}

1 School of Conservation, Esplanaden 34, 1263 Copenhagen K, Denmark.

${ }^{2}$ Conservation Centre Vejle, Maribovej 10, 7100 Vejle, Denmark. ${ }^{3}$ Laboratories of IRPA/KIK, Parc du Cinquantenaire 1, 1000 Brussels, Belgium.

\section{Acknowledgements}

The authors would like to thank Ulrikka S. Gernes for valuable information and discussion, and Project Director Connie Barfoed, Herlev Hospital, and Special Advisor Inger Krog, Ministry of Culture, Denmark, for allowing investigation and sampling of the folding doors.

\section{Competing interests}

The authors declare that they have no competing interests.

\section{Ethics approval and consent to participate}

Not applicable.

\section{Funding}

Not applicable.

\section{Publisher's Note}

Springer Nature remains neutral with regard to jurisdictional claims in published maps and institutional affiliations.

Received: 21 February 2018 Accepted: 4 May 2018 Published online: 11 May 2018

\section{References}

1. Gernes US, Hornung PM. The medicine of colours. Poul Gernes and Copenhagen University Hospital at Herlev. 1st ed. Copenhagen Valby: Borgens forlag; 2003.

2. Lauridsen CB, Sanyova J, Simonsen KP. Analytical study of modern paint layers on metal knight shields: the use and effect of Titanium white. Spectrochim Acta A Mol Biomol Spectrosc. 2014;124:638-45.

3. Laver M. Titanium dioxide whites. In: FitzHugh EW, editor. Artists' pigments. A handbook of their history and characteristics, vol. 3. Oxford: Oxford University Press; 1997. p. 295-355.

4. Burgio L, Clark RJH. Library of FT-Raman spectra of pigments, minerals, pigment media and varnishes, and supplement to existing library of Raman spectra of pigments with visible excitation. Spectrochim Acta A Mol Biomol Spectrosc. 2001;57:1491-521.

5. Bell IM, Clark RJH, Gibbs PJ. Raman spectroscopic library of natural and synthetic pigments (pre- 1850 AD). Spectrochim Acta A Mol Biomol Spectrosc. 1997;53:2159-79.

6. Rosasco GJ, Blaha JJ. Raman microprobe spectra and vibrational mode assignments of talc. Appl Spectrosc. 1980;34:140-4

7. Šontevska V, Jovanovski G, Makreski P. Minerals from Macedonia. Part XIX. Vibrational spectroscopy as identificational tool for some sheet silicate minerals. J Mol Struct. 2007:834-836:318-27.

8. Carbó MTD, Martínez VP, Adelantado JVG, Reig FB, Moreno MCMM. Fourier transform infrared spectroscopy and the analytical study of sculptures and wall decoration. J Mol Struct. 1997;410-411:559-63.

9. Burke P, Curry CJ, Davies LM, Cousins DR. A comparison of pyrolysis mass spectrometry, pyrolysis gas chromatography and infra-red spectroscopy for the analysis of paint resins. Forensic Sci Int. 1985;28:201-19.

10. Cappitelli F. THM-GCMS and FTIR for the study of binding media in Yellow Islands by Jackson Pollock and Break Point by Fiona Banner. J Anal Appl Pyrolysis. 2004;71:405-15.

11. Ploeger R, Scalarone D, Chiantore O. The characterization of commercial artists' alkyd paints. J Cult Heritage. 2008;9:412-9.

12. Duce C, Della Porta V, Tiné MR, Spepi A, Ghezzi L, Colombini MP, Bramanti E. FTIR study of ageing of fast drying oil colour (FDOC) alkyd paint replicas. Spectrochim Acta A Mol Biomol Spectrosc. 2014;130:214-21.
13. Anghelone $M$, Jembrih-Simbürger $D$, Schreiner $M$. Influence of phthalocyanine pigments on the photo-degradation of alkyd artists' paints under different conditions of artificial solar radiation. Polym Degrad Stab. 2016;134:157-68

14. İşeri-Çă̆lar D, Baștürk E, Oktay B, Kahraman MV. Preparation and evaluation of linseed oil based alkyd paints. Prog Org Coat. 2014;77:81-6.

15. Wei S, Pintus V, Schreiner M. A comparison study of alkyd resin used in art works by Py-GC/MS and GC/MS: the influence of aging. J Anal Appl Pyrolysis. 2013;104:441-7.

16. Challinor JM. Structure determination of alkyd resins by simultaneous pyrolysis ethylation. J Anal Appl Pyrolysis. 1991;18:233-44.

17. Scalarone D, Lazzari M, Chiantore O. Ageing behaviour and pyrolytic characterisation of diterpenic resins used as art materials: colophony and Venice turpentine. J Anal Appl Pyrolysis. 2002;64:345-61.

18. Modugno F, Ribechini E. GC/MS in the characterisation of resinous materials. In: Colombini MP, Modugno F, editors. Organic mass spectrometry in art and archaeology. Chichester: Wiley; 2009. p. 215-35

19. Kokkori M, Sutherland K, Boon J, Casadio F Vermeulen M. Synergistic use of Py-THM-GCMS, DTMS, and ESI-MS for the characterization of the organic fraction of modern enamel paints. Heritage Sci. 2015;3:30.

20. Schilling MR, Heginbotham A, van Keulen H, Szelewski M. Beyond the basics: a systematic approach for comprehensive analysis of organic materials in Asian lacquers. Stud Conserv. 2016;61:3-27.

21. Frost RL. Raman microscopy of selected chromate minerals. J Raman Spectrosc. 2004;35:153-8.

22. Christiansen MB, Sørensen MA, Sanyova J, Bendix J, Simonsen KP. Characterisation of the rare cadmium chromate pigment in a 19th century tube colour by Raman, FTIR, X-ray and EPR. Spectrochim Acta A Mol Biomol Spectrosc. 2017:175:208-14

23. Simonsen KP, Christiansen MB, Vinum MG, Sanyova J, Bendix J. Single crystal X-ray structure of the artists' pigment zinc yellow. J Mol Struct. 2017;1141:322-7.

24. Herbst W, Hunger K. Industrial organic pigments. Production, properties, applications. 2nd ed. Weinheim: Wiley-VCH; 1997.

25. Newman R. Chromium oxide greens. In: Fitzhugh EW, editor. Artists' pigments. A handbook of their history and characteristics, vol. 3. Oxford: Oxford University Press; 1997. p. 273-93.

26. Scherrer NC, Stefan Z, Francoise D, Annette F, Renate K. Synthetic organic pigments of the 20th and 21st century relevant to artist's paints: Raman spectra reference collection. Spectrochim Acta A Mol Biomol Spectrosc. 2009;73:505-24.

27. Fremout W, Saverwyns S. Identification of synthetic organic pigments: the role of a comprehensive digital Raman spectral library. J Raman Spectrosc. 2012:43:1536-44.

28. Cucci C, Bartolozzi G, De Vita M, Marchiafava V, Picollo M, Casadio F. The colors of Keith Haring: a spectroscopic study on the materials of the mural painting Tuttomondo and on reference contemporary outdoor paints. Appl Spectrosc. 2016;70:186-96.

29. Vandenabeele P, Moens L, Edwards H, Dams R. Raman spectroscopic database of azo pigments and application to modern art studies. J Raman Spectrosc. 2000;31:509-17.

30. Lomax SQ, Lomax JF, Luca-Westrate AD. The use of Raman microscopy and laser desorption ionization mass spectrometry in the examination of synthetic organic pigments in modern works of art. J Raman Spectrosc. 2014;45:448-55.

31. Lauridsen CB, Sanyova J, Simonsen KP. Raman analysis of complex pigment mixtures in 20th century metal knight shields of the order of the elephant. Spectrochim Acta A Mol Biomol Spectrosc. 2015;150:54-62.

32. Gautier G, Bezur A, Muir K, Casadio F, Fiedler I. Chemical fingerprinting of ready-mixed house paints of relevance to artistic production in the first half of the twentieth century. Part I: inorganic and organic pigments. Appl Spectrosc. 2009:63:597-603.

33. Helwig K, Thibeault M-E, Poulin J. Jack Chambers' mixed media paintings from the 1960s and 1970s: painting technique and condition. Stud Conserv. 2013;58:226-44

34. Dredge P, Schilling MR, Gautier G, Mazurek J, Learner T, Wuhrer R. Lifting the lids off Ripolin: a collection of paint from Sidney Nolan's studio. J Am inst Conserv. 2013;52:213-26. 